НАУКИ О ЗЕМЛЕ

"НАУКА. ИННОВАЦИИ. ТЕХНОЛОГИИ", №4, 2019

25.00 .24

ЭКОНОМИЧЕСКАЯ, СОЦИАЛЬНАЯ, ПОЛИТИЧЕСКАЯ

УДК 913(470.63) И РЕКРЕАЦИОННАЯ ГЕОГРАФИЯ

Зольникова Ю.Ф. Северо-Кавказский фредеральный университет, г. Ставрополь, Россия zolnst@mail.ru

\title{
ФОРМИРОВАНИЕ КУРОРТНОГО РЕГИОНА КАВКАЗСКИЕ МИНЕРАЛЬНЫЕ ВОДЫ В СОВЕТСКИЙ ПЕРИОД
}

Введение: $\quad$ Курортный регион Кавказские Минеральные Воды (KMB) является уникальной территорией, которая обладает разнообразными рекреационными ресурсами: гидроминеральными, грязевыми, климатическими, экскурсионными. На базе многочисленных рекреационных ресурсов на рубеже XVIII-XIX вв. сфрормировались крупнейшие бальнеологические центры страны - городакурорты Пятигорск, Кисловодск, Ессентуки и Железноводск. На протяжении XIX-XX вB. происходило формирование курортного региона.

Материалы и методы

исследований: $\quad$ В статье проведен анализ документов по развитию лечебных и курортных местностей в СССР и показаны особенности их реализации в курортном регионе Кавказские Минеральные Воды в советский период. Прослеживается характер застройки, формирование экономики и развитие инфрраструктуры в курортном регионе Кавказские Минеральные Воды.

Результаты исследований

и их обсуждение: $\quad$ В советский период курортный регион Кавказские Минеральные Воды превращаются в крупнейший санаторно-курортный комплекс страны; города Кисловодск, Ессентуки, Пятигорск и Железноводск приобрели курортное значение всесоюзного масштаба. В советский период происходило масштабное курортное строительство, в том числе курортной инфраструктуры, благоустройство городов-курортов.

Выводы: $\quad$ Формирование курортного региона Кавказские Минеральные Воды, специфика и характер его застройки в советский период были обусловлены курортной функцией региона.

Ключевые слова: Кавказские Минеральные Воды, курортный регион, курорт, минеральные воды, рекреационные ресурсы. 
Zolnikova Yu.F. North-Caucasus Federal University, Stavropol, Russia zolnst@mail.ru

\section{FORMATION OF THE RESORT REGION CAUCASIAN MINERAL WATERS DURING THE SOVIET PERIOD}

Introduction:

The resort region of Caucasian Mineral Waters (CMS) is a unique territory that has a variety of recreational resources: hydromineral, mud, climatic, and excursion. On the basis of numerous recreational resources at the turn of the XVIII-XIX centuries. the largest balneological centers of the country were formed - the resort towns of Pyatigorsk, Kislovodsk, Essentuki and Zheleznovodsk. During the

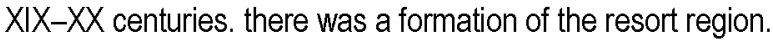

Materials and methods

of research:

The article analyzes the documents on the development of medical and spa areas in the USSR and shows the features of their implementation in the resort region of Caucasian Mineral Waters in the Soviet period. The nature of development, the formation of the economy and the development of infrastructure in the resort region of Caucasian Mineral Waters are traced.

Research results and

their discussion: In the Soviet period, the resort region of Caucasian Mineral Waters turned into the largest sanatorium-resort complex of the country; the cities of Kislovodsk, Essentuki, Pyatigorsk and Zheleznovodsk acquired resort significance on an all-Union scale. In the Soviet period, large-scale resort construction took place, including resort infrastructure, and the improvement of resort towns.

Conclusions: $\quad$ The formation of the resort region of Caucasian Mineral Waters, the specifics and nature of its development in the Soviet period were determined by the resort function of the region.

Keywords: $\quad$ Caucasian Mineral Waters, resort region, resort, mineral waters, recreational resources. 


\section{Введение}

Кавказские Минеральные Воды (КМВ) - один из старейших курортных регионов России, объединяет группу городов-курортов Кисловодск, Ессентуки, Железноводск, Пятигорск. Формирование курортного региона проходило в несколько этапов, отличающихся по характеру и особенностям рекреационной деятельности в регионе. На формирование КМВ оказывало влияние хозяйственное освоение территории и изменение потребностей российского общества в рекреационных услугах.

Государственное значение региона Кавказские Минеральные Воды и необходимость его обустройства было принято еше в 1803 г. На протяжении XIX в. в регионе осуществлялись постройки, связанные с курортной функцией. Но самые значительные преобразования в обустройстве курортного региона и городов-курортов Кавказских Минеральньх Вод произошли в советский период.

\section{Материалы и методы исследований}

В качестве источников использовались и анализировались научные труды и монографии исследователей Кавказских Минеральных Вод. Изучены документы (декреты, постановления и др.) по лечебным местностям, по отдельным городам-курортам региона Кавказские Минеральные Воды и показаны особенности их реализации в курортном регионе Кавказские Минеральные Воды в советский период. Анализ и обобщение перечисленных материалов позволил проследить характер застройки, формирование экономики и развитие инфраструктуры в регионе в соответствии с рекреационной функцией Кавказских Минеральных Вод.

\section{Результаты исследований и их обсуждение}

В советский период регион Кавказские Минеральные Воды становится одним из крупнейших рекреационных районов страны. На протяжении советского периода осуществляется активное строительство и оснащение лечебно-оздоровительных и туристских объектов (санаториев, гостиниц, туристических баз и др.), происходит расцвет курортов и их благоустройство. Курорты региона КМВ становятся популярным местом лечения и отдыха.

В советском периоде в формировании курортного региона Кавказские Минеральные Воды можно выделить два этапа: довоенный (20-е - начало 40-х гг. XX в.) и послевоенный (конец 40-х - 80-е гг. ХХ в.).

Довоенный этап связан с изменением организации учреждений рекреации, предприятий транспорта, сферы обслуживания курортных городов. На этом этапе начинается процесс реконструкции курортного региона, разрабатываются схемы районной планировки. 
Годы гражданской войны тяжело отразились на Кавказских Минеральных Водах: лучшие здания на курортах были разрушены; сильно пострадали лечебные учреждения, дачи и гостиницы; парки и бульвары вырубались на дрова. Необходимо было восстанавливать курорты.

Декретом СНК от 4 апреля 1919 г. «О лечебньх местностях общегосударственного значения» все курорты были национализированы, начался новый этап в развитии Кавказских Минеральных Вод [2]. Декрет предопределил основные принщипы курортного строительства на многие годы. В районе Кавказских Минеральных Вод началось активное освоение изученных рекреационных ресурсов и крупное курортное строительство.

В 1917 г. курорты Ессентуки и Железноводск получают статус городов. На курортах закладываются основы нового курортного лечения. На Кавказских Минеральных Водах определяется четкий лечебный профиль курортов; санаторное и амбулаторное обслуживание стало основной формой организации рекреационной деятельности лечащихся [1].

В целях создания санаторно-курортного хозяйства и условий для массового курортного лечения были освобождены все места, пригодные для размещения новых санаториев и пансионатов. В 1925 г. все наиболее крупные здания были переоборудованы в санатории, началось строительство новых государственных и профсоюзных здравниц.

В 1926-1927 гг. санаторно-курортный комплекс курортного региона Кавказские Минеральные Воды включал 48 специализированных санаториев на 7,2 тыс. мест, 19 водолечебниц на 543 кабины, 4 курортные поликлиники. Курорты обслуживали 73 тыс. человек, что в 1,7 раза превышало численность отдыхающих на курортах района в 1914 г. Через три года численность отдыхающих возросла до ста тысяч человек, а в 1939 г. число лечашихся на курортах Кавказских Минеральных Вод достигло 146 тыс. человек [4].

На этом этапе благодаря геологоразведочным работам увеличились запасы гидроминеральных ресурсов в регионе. В Кисловодске были открыты источники доломитного (1928 г.) и сульфатного (1934 г.) нарзанов, в Ессентуках - широко известные в настоящее время источники Ессентуки 17, буровые скважины №1 и №2 [6].

В 30-е гг. XX в. разрабатываются проекты районных планировок курортных районов, в том числе рекреационного района Кавказские Минеральные Воды, а также генеральные планы городов-курортов [7]. С 1935 года стали осуществляться широкие мероприятия по коренной реконструкции курортов. Проектные решения по курортным районам того времени отличались широтой. Многие методологические и научные положения выдвигались впервые. Это был период формирования теоретических основ курортного строительства с проверкой их на практике [3].

В 1935 г. ЦК ВКП(б) принял постановление о генеральной реконструкции Кавказских Минеральных Вод, которую намечалось осуществить в тече- 
ние 15 лет. Архитектурно-планировочная мастерская Народного комиссариата коммунального хозяйства под руководством профессора В.Н. Семенова приступила к работе над «Схемой районной планировки Кавказских Минеральных Вод». Важной особенностью этого проекта явилось комплексное планирование всех элементов хозяйственного комплекса региона Кавказских Минеральных Вод (санаторно-курортного хозяйства, промышленности, общественной инфраструктуры, а также пригородного хозяйства) с учетом интересов всего района [13].

В проекте развития Кавказских Минеральных Вод были выдвинуты прогрессивные концепции планировочной организации курортов, развития транспорта, озеленения и т.д. Курортные города рассматривались как центры концентрации рекреационной деятельности отдыхающих. В них предусматривался приоритет в развитии производств, обслуживающих нужды курортов, и ограничение до минимума производств, несвойственных курортным городам. Намечался вывод из курортных городов вредных в санаторно-гигиеническом отношении, а также неуместных курортным городам предприятий. В эти годы вступили в строй 36 санаториев.

В 1935 г. курорты Кавказских Минеральных Вод посетило 200 тысяч человек, из них 40\% - амбулаторно, на расчетный срок предусматривалось увеличение посещаемости примерно в три раза - до 600 тысяч человек.

Проект районной планировки Кавказских Минеральных Вод 1935 года в отличие от прошлых проектов рассматривал систему поселений курортного района широко, включая в ее состав, кроме курортных городов, транспортный центр района, а также сельские населенные пункты, расположенные в их пригородах [13]. Таким образом, в проекте развития Кавказских Минеральных Вод были выдвинуты прогрессивные конщепции планировочной организации курортов, развития транспорта, озеленения и др.

Регион Кавказские Минеральные Воды проектировался как единый целостный организм, тесно связанный дорожной сетью, развитием сельского хозяйства, системой водоснабжения, зеленых насаждений и другими взаимосвязями, которые следовали из назначения района как важнейшей здравницы $\mathrm{CCCP}[11]$.

Одной из важных и новых проблем в проекте была разработка перспектив развития туризма. Туристы делились на категории: по виду лечения, географии приезда, продолжительности посещения курортного района [3]. Предусматривалось и создание специальных туристических маршрутов.

В 1936 г. была электрифицирована железная дорога, соединяющая г. Минеральные Воды со всеми курортами региона Кавказских Минеральных Вод [6].

К 40-м гг. ХХ века в регионе разворачивается строительство санаториев круглогодичной эксплуатации. Самым крупным курортом региона, а также 
крупнейшим кардиологическим курортом страны становится Кисловодск, в котором лечилось 54,5\% от общего числа курортников Кавказских Минеральных Вод [1]. Вторым по числу курортников был Ессентуки, специализировавшийся, как и Железноводск, на лечении заболеваний желудочно-кишечного тракта. Пятигорск, на который приходилось лишь 10\% курортников Кавказских Минеральных Вод, развивался как многопрофильный курорт, что было связано с концентрацией в городе непрофильных для городов-курортов предприятий и учреждений.

В этот период в структуре туристско-рекреационного комплекса региона не произошло значительных изменений. Как и прежде главную роль играл оздоровительный туризм, на развитие которого были брошены все силы. Однако произошли изменения в форме организации рекреационной деятельности. Санаторное и амбулаторное обслуживание стали основной формой организации рекреационной деятельности. Увеличился рекреационный период. Если в дореволюционное время он составлял от четырех до шести месяцев, то в советский период стал охватывать весь год. Курорты начинают обретать черты организованного функционирования. Вся структура туризма подчинялось определенным ритмам и потокам отдыхающих.

В годы Великой Отечественной войны все здравницы региона Кавказских Минеральных Вод были превращены в госпитали, где за весь период военных действий получили медицинскую помощь более 900 тысяч раненых.

Послевоенный этап - время становления региона как крупного рекреационного центра. Он характеризуется активным строительством рекреационных учреждений различного профиля на основе освоенных ресурсов, продолжают развиваться курорты, для рекреационного использования осваиваются новые территории, с каждым годом увеличивается поток рекреантов.

После окончания войны правительством были направлены крупные целевые средства на восстановление Кавказских Минеральных Вод и превращение их в один из основных курортных районов СССР. Уже в 1950 г. на курортах Кавказских Минеральных Вод лечилось свыше 200 тыс. человек, а в 1956 г. - почти 300 тыс. человек [4].

Более десяти лет с 1949 г. шла разведка углекислых минеральных вод Кисловодского, Подкумского, Кумского месторождений для определения возможностей роста курортов. В 1960-1970-е гг. в регионе продолжается активное строительство ведомственных санаторно-курортных комплексов, строится большая часть ныне действующих санаториев, реставрируются санатории старой постройки. При этом изменяется территориальная структура санаторно-курортного хозяйства - более высокие, чем в Кисловодске, темпы роста ее емкости, в отличие от довоенного периода, отмечаются на других курортах района. Снижаются относительные показатели Кисловодска в рекреационном обслуживании лечащихся. 
С начала 60-х годов $\mathrm{XX}$ в. Гипрогором был выполнен ряд проектнопланировочных работ по региону Кавказские Минеральные Воды, включающий разномасштабные градостроительные проработки от проектов, охватывающих территорию КМВ в целом до генеральных планов отдельных городов и проектов детальной планировки курортных, жилых и общественных комплексов [5].

За период реализации генеральных планов, разработанных Гипрогором, в области планировки и застройки курортного региона и городов-курортов имелись определенные успехи. Были осушествлены работы по благоустройству, озеленению, развитию транспортных путей, сносу ветхих строений и реконструкции существуюшего санаторного фонда, не отвечающего требованиям, велось строительство новых санаторно-курортных комплексов, объектов культурно-бытового назначения и др.

С 1970-х годов, в результате интенсивного развития лечебной деятельности на курортах Кавказских Минеральных Вод, гидроминеральная база Ессентуков и Кисловодска становится недостаточной для обеспечения их потребностей в минеральной воде. Курорты начинают активно осваивать и использовать ресурсы пригородных районов (Кисловодск минеральную воду Березовского месторождения, Ессентуки - северо-ессентукских месторождений). Масштабы курортного и промышленного строительства привели к значительному территориальному росту городов. Появились новые курортные зоны в Кисловодске - Запикетный район, в Ессентуках - Заполотнянский [1]. В 1980-е гг., в связи с увеличившимся потоком курортников, строительство санаториев продолжается. К 1980 г. на Кавказских Минеральных Водах функционировало 82 санатория (в том числе 37 профсоюзных почти на 21 тыс. мест) и 16 пансионатов (около 2 тыс. мест). Работали 2,5 тыс. врачей и около 7 тыс. лиц среднего медицинского персонала. В 1980 г. на курортах Кавказских Минеральных Вод отдыхало и лечилось около 800 тыс. человек, а в 1986 г. - около 1 млн человек [4].

Хотя основным профилем туристско-рекреационной сферы региона Кавказские Минеральные Воды этого этапа был лечебный, но все большее развитие стали получать различные формы туризма. Это объяснялось, вопервых, наличием в регионе богатого туристского потенциала, во-вторых, возрастали потребности рекреантов. Отдыхающих, приезжающих на курорты в лечебных целях, интересовала и развлекательная программа, основу которой составлял экскурсионный туризм. Основными туристскими центрами стали Пятигорск и Кисловодск, которые обладали значительным потенциалом и могли предложить различного рода туристские услуги. В результате регион Кавказские Минеральные Воды во второй половине послевоенного этапа являлся важнейшим центром экскурсионного туризма (здесь проходили 16 всесоюзных и 12 местных маршрутов); крупным экскурсионным цент- 
ром Ставрополья, обслуживающим более 2,8 млн экскурсантов - $80 \%$ общего числа экскурсантов края; основной детской оздоровительной базой Ставрополья, где размещалась 47\% пионерских лагерей края; популярным местом кратковременного отдыха жителей Ставрополья и других регионов Северного Кавказа и Закавказья [12].

\section{Выводы}

Таким образом, в советский период в формировании курортного региона Кавказские Минеральные Воды значительно выросли масштабы рекреационной деятельности. Курорты превратились в крупные рекреационные центры. Туризм приобрел организованный характер, имеющий четкую структуру. Каждый курорт региона КМВ имел свои определенные функции, свой лечебный профиль. Также активно начинает развиваться и экскурсионно-познавательный туризм, основу которого составляли природные, культурные и исторические достопримечательности региона.

\section{Библиографический список}

1. Белозеров В.С. Кавказские Минеральные Воды: эволюция системы городов эколого-курортного региона. М., 1997. 80 C.

2. Декрет СНК от 20 марта 1919 года «О лечебных местностях общегосударственного значения» // Известия ВЦИК. 1819. 15 мая.

3. Зольникова Ю.Ф. Формирование территориальной планировочной структуры курортного региона Кавказские Минеральные Воды в советский период // Вестник Северо-Осетинского государственного университета им. К.Л. Хетагурова. Общественные науки. 2014. №3. С. 307-309.

4. Краснокутская Л.И., Михайленко В.И. Управление курортами Кавминвод (1803-2003): страницы российской истории. Пятигорск, 2004. $160 \mathrm{c}$.

5. Материалы отдела информационного обеспечения градостроительной деятельности муниципального учреждения «Управления архитекторы и градостроительства администрации города Пятигорска».

6. Пантелеев И.Я. Очерк истории изучения и развития Кавказских Минеральных Вод. М., 1955. 204 с.

7. Перцик Е.Н. Районная планировка. Географические аспекты. М.: Мысль, 1973.

8. Постановление НК Здравоохранения «О признании за некоторыми лечебными местностями общегосударственное значение и о распространении на них действия декрета от 4 апреля 1919 года статьи №265 // Известия ВЦИК от 29 мая 1919 г. 
9. Постановление СНК о домах отдыха // Известия ВЦИК. 1921. 19 мая.

10. Постановление ВЦИК и СНК «О курортах Крыма, Кавказа и Кубани» от 11 июня 1921 года // Постановления КПСС и Советского правительства об охране здоровья народа. М., 1958.

11. Проект зон охраны памятников истории и культуры города Кисловодска. Т. 3. Стадия НРО. М., 1986.

12. Рекреационные районы Северного Кавказа // Рекреационные ресурсы. Часть 2. Условия и ресурсы отдыха и туризма. Издательство Ростовского университета, 1982. С. 49-242.

13. Семенов В.Н. Вопросы планировки // Академия архитектуры. -1935. № 4. C. 39-43.

\section{References}

1. Belozerov V.S. Caucasian Mineral Waters: the evolution of the city system of the ecologically resort region. M., 1997. $80 \mathrm{p}$.

2. Decree of the Council of People's Commissars of March 20, 1919 "On medical areas of national importance" // News of the All-Russian Central Executive Committee. 1819. May 15.

3. Zolnikova Yu.F. The formation of the territorial planning structure of the resort region of Caucasian Mineral Waters in the Soviet period // Bulletin of the North Ossetian State University. K.L. Khetagurova. Social Sciences. 2014. No. 3. S. 307-309.

4. Krasnokutskaya L.I., Mikhailenko V.I. Resort Management Cavminvod (1803-2003): pages of Russian history. Pyatigorsk, 2004. $160 \mathrm{~s}$.

5. Materials of the department of information support for urban development of the municipal institution "Office of Architects and Urban Planning of the Administration of Pyatigorsk."

6. Panteleev I.Ya. Essay on the history of the study and development of Caucasian Mineral Waters. M., 1955. 204 p.

7. Pertsik E. N. District planning. Geographical aspects. M.: Thought, 1973.

8. Decision of the NK Healthcare "On the recognition of national importance for certain treatment areas and on the extension to them of the decree of April 4, 1919, article No. 265 // News of the AllRussian Central Executive Committee of May 29, 1919.

9. The decision of the Council of People's Commissars on holiday homes // News of the All-Russian Central Executive Committee. 1921. May 19

10. Decree of the All-Russian Central Executive Committee and the Council of People's Commissars "On the Resorts of Crimea, the Caucasus and the Kuban" dated June 11, 1921 // Decisions of the CPSU and the Soviet Government on the protection of public health. M., 1958.

11. The project of zones for the protection of historical and cultural monuments of the city of Kislovodsk. T. 3. Stage NRA. M., 1986. 
12. Recreational areas of the North Caucasus // Recreational resources. Part 2. Conditions and resources of recreation and tourism. Publishing house of the Rostov University, 1982. S. 49-242.

13. Semenov V.N. Planning issues // Academy of Architecture. 1935. No. 4. S. 39-43.

Поступило в редакцию 20.11.2019, принята к публикации 02.12.2019

\section{O6 авторах}

Зольникова Юлия Федоровна, кандидат географических наук, доцент, доцент кафедры социально-экономической географии, геоинформатики и туризма Северо-Кавказский федеральный университет.

Тел. (928) 631-88-30.

E-mail: zolnst@mail.ru.

\section{About the authors}

Zolnikova Yuliya Fedorovna, candidate of geographical Sciences, associate Professor, associate Professor of the Department of socio-economic geography, Geoinformatics and tourism North Caucasus Federal University, Pushkin str., 1, building 2, AUD. 120.

Tel. (928) 631-88-30.

E-mail: zolnst@mail.ru. 